\title{
Unmet health care needs of elderly residing on urban areas of Sunsari District, Nepal. A Cross Sectional Study
}

Mukesh Poudel ( $\nabla$ poudelmuk@gmail.com )

Ministry of Health and Population Nepal https://orcid.org/0000-0003-4693-4418

Asmita Ojha

Tribhuvan University Institute of Medicine

Deepak Kumar Yadav

BP Koirala Institute of Health Sciences

Ram Bilakshan Sah

BP Koirala Institute of Health Sciences

Avaniendra Chakravartty

BP Koirala Institute of Health Sciences

Anup Ghimire

BP Koirala Institute of Health Sciences

Research article

Keywords: Elderly, Unmet health care needs, Nepal

Posted Date: February 19th, 2020

DOI: https://doi.org/10.21203/rs.2.18815/v2

License: () (i) This work is licensed under a Creative Commons Attribution 4.0 International License. Read Full License 


\section{Abstract}

Background: The global aging population is in increasing trend. Morbidity increases with age and enhances the burden of health problems that result in new challenges to meet additional demands. There can be various types of issues such as health problems, health care utilization, physical and social care which should be carefully assessed and addressed. This study aimed to assess the unmet health care needs among elderly.

Methods: A Community based, House to House, Cross-sectional study was conducted in urban areas of the sunsari district using face to face interviews. The sample size of 530 elderly was selected by a systematic proportionate random sampling technique.

Results: This study unfurled the prevalence of unmet need for consultation for Nearsightedness $52.3 \%$, Farsightedness $53.7 \% \%$, Hearing $79.7 \%$, Dental $79.4 \%$, Hypertension 6.7\%, Diabetes 3.9\%, CVD $5.3 \%$ among those with these specific health needs and of at least one Unmet Health care need to be $64.9 \%$ among the studied participants. At least one unmet health need was significantly associated with higher odds among elderly age more than 70 , of dalit and janajati ethnicity, illiterate, poor, those with difficulty leaving home, the distance of health facility $>30$ mins, and those with depressive symptoms.

Conclusion: The study highlighted the higher prevalence and associated factors related to unmet health care needs among the elderly which should be addressed to promote healthy ageing. There is an urgent need to promote geriatric health services and make it available at the primary health care level the first level of contact with a national health system.

\section{Background}

Ageing is universal and inevitable biological process that renders physical, psychological, and social transformation.(1) Like global megatrends Nepal is also witnessing an increasingly ageing population with its ageing population $8.1 \%$ in 2011.(2) Life expectancy has increased from 41 years in 1971 to 68 years in 2012 and the growth rate of ageing population is around 3.5\% and is in increasing trend while total population growth rate of Nepal is $1.4 \%$ and is declining. (3) The Global Age Watch Index (GAWI) of Help age International 2015 proclaimed Switzerland as the most suitable country for the old where Nepal ranks 70 among 96 in the index.(4) WHO defines Healthy Ageing "as the process of developing and maintaining the functional ability that enables wellbeing in older age".(5) Different studies done globally have explored the existence of inequalities in health services and perceived unmet needs for healthcare in the elderly population due to various reasons.(6-9) A study among Spanish elderly, have found the lower survival probabilities for individuals with unmet needs and unmet needs were associated with a higher probability of mortality at the end of follow-up, with excess risk ranging from $10 \%$ to $155 \%$. (10)

Morbidity increases with age resulting in new challenges to meet the additional demands thus enhancing the burden of health problems.(11) The increasing aging population and the sustained shift in population age structure poses an array of challenges to overall health services and policy makers to combat with different morbidity patterns among elderly residing in Nepal.(12,13) Also to fulfil the pledge of the 2030 agenda for sustainable development that "no one will be left behind" it is essential to prepare for the economic and social shifts associated with an ageing population with implications from all sectors of society.

Unmet health care needs can be defined as the difference between the health care services deemed necessary to deal with a health problem and the actual services received.(6) The problems that are not being addressed by the existing service delivery system can be highlighted by assessment of unmet needs, also it considers both health status and the receipt of assistance.(15) Different factors like health status, availability and accessibility of health care services may influence the patterns of health care utilization depending upon economic, psychological, behavioral and epidemiological factors. The assessment of the factors that influence health care utilization and unmet needs of the elderly prevalent in society will be helpful to inform the policy as the social protection is limited and many of the needs of elderly are unmet with a lack of sensitivity and awareness regarding the rights and protection of the elderly. (3)

\section{Methods}

The aim of this study was to assess the unmet health care needs among elderly residing in urban areas (Itahari and Dharan) of Sunsari district.

This was a Community Based Cross Sectional Study within a period of one year from September 2017 to August 2018 in selected wards (administrative divisions of a city) of Itahari and Dharan two sub-metropolitian cities of Sunsari district. People of Age 60 years and above willing to participate in the study were included in the study and those with diagnosed mental health problems under medication, severely ill who needed emergency care were excluded from the study. Sample Size was calculated at $95 \%$ confidence interval and $85 \%$ power taking the $26.2 \%$ prevalence of unmet health care needs in people suffering with hypertension from study done in Bhaktapur District. (11) The total calculated sample size was 530.

Systematic proportionate random sampling was done to obtain the representative sample. The proportion was based on total population of metropolitian and population in each selected ward. Wards are the small administrative divisions of districts. Eight wards were selected from each sub-metropolitian randomly using lottery method. Selected ward was visited and bottle was rotated at the middle junction and first household was chosen in the direction that bottle pointed. Then every $3^{\text {rd }}$ house was taken for the study until the desired sample size was fulfilled. In case sample criteria, didn't meet in the selected household the adjacent household with sample criteria was taken for the data collection. If there were more than one elderly in one house the participant was chosen randomly by lottery method.

Face to face interview was done using semi-structured pre-tested Questionnaire to gather information regarding demographics and other variables. Participants reporting a chronic disease were asked to identify their problem(s) in a list of 5 chronic diseases used by package for Essential Noncommunicable diseases Nepal.(16) Physical and sensory functional limitations were assesed with the ability to see newspaper print clearly, the ability to see the face of someone $4 \mathrm{~m}$ away clearly, the ability to hear distinctly what is said in a conversation with one other person and the ability to chew hard foods 
without difficulty. The evaluation of activity restrictions examined the five activities of daily living (ADL) included in the Katz index, i.e. bathing, dressing, toileting, transferring, continence and feeding. Homebound status was defined as incapacity to leave the home without help.(6) Unmet health care need was defined as situations in which a participant needed health care but did not receive it. Two questions were used, the first question evaluating the need of care and the second question dealing with the use of health care resources.(6) Depressive symptoms were evaluated using Beck Depression Inventory $2^{\text {nd }}$ edition (BDI-II). The BDI-II scale is validated for use in Nepal and the translated Nepali version was used.(17) In non-clinical populations, scores above 20 indicate depression, the Cronbach's Alpha based on standardized items when tested for all the 21 items on BDI-II scale has shown a good consistency of 0.76 . (18)

Ethical Clearance was obtained from institutional review committee of B.P Koirala Institute of Health Sciences. (Code No. IRC/1163/017) The permission to coduct study in respective area was obtained from municipality office.

Statistical analysis was done using the statistical package for social sciences. Descriptive analysis is presented in frequency, percentage and appropriate test of significance (chi-square test) was done for bi-variate analysis. Multivariate binary logistic regression was then further done to find the adjusted odds ratio for the determinants. Statistical significance is tested with a $95 \%$ confidence interval and p-value less than 0.05 is considered significant.

The term elderly has been used as a Senior citizen where "Senior Citizen" means a citizen of Nepal having completed the age of sixty years.(19)

The participants dwelling is stated as kachha if floor, wall and roof none were built with concrete material, semipukka if one of the parts was made of concrete material and pukka if all the materials were made of concrete materials.

Common Health problems were sensory functional limitations very commonly occurring due to ageing. (Nearsightedness, Farsightedness, Hearing and Chewing).(6)

Common presenting symptoms in the elderly were inquired by asking if they have any problems from a list of common presenting symptoms in elderly obtained by a study in Chandigarh.(20)

Depressive symptoms were referred to as scores above 20 in BDI-II.(18)

Ethnicity was categorized as per the HIMS (Health Information Management System) classification of ethnicity, which was based on Central Bureau of Statistics Population Monograph of Nepal. (21)

Poverty line: Poverty line was assessed according to the World Bank global poverty line revised in October 2015 (US\$1.90 per day). Exchange rates used is the one fixed by Nepal Rastra Bank at the time of analysis on $1^{\text {st }}$ October 2018 USD $1 \$=115$ NRs. (22-24)

Per capita income was considered the income of a person annually which was generated by dividing family income annually divided by the number of family members.

The social activity was evaluated by the type of activity, frequency of activity per week, and time spent on each activity that they were involved in. (25)

\section{Results}

\section{Socio-demographic characteristics}

This study constituted $49.1 \%$ of females. The mean age of the participant in this study was 72.2 years with a standard deviation of 8.1 and age ranging from 60 years to 101 years. Most participants (41.1\%) belonged to the age group 60-69 years, brahmin/chettri ethnicity (45.6\%), Hindu (85.7\%) by religion. In the study participants, $63.8 \%$ were currently a couple, $47.4 \%$ were living in the pukka house and $2.6 \%$ of the elderly were living alone. More than half (56.0\%) participants were below the poverty line and $20.4 \%$ of the participants had per capita income less than NRs 43,200 (USD - 375\$). The majority of the participants (67.7\%) had no schooling, and regarding work status, the majority (49.2\%) were not working. (Table 1)

Table 1 Socio-demographic factors of participants $(n=530)$

\section{Felt needs and unmet health care needs for common health problems}

The felt need for common health problems was highest for those with nearsightedness out of which $52.3 \%$ have not consulted and 55.1\% of those who consulted didn't get the required treatment. Similarly, a higher proportion of unmet need for consultation with the felt need (79.7\%) and unmet need for treatment in those who consulted (90.6\%) was seen in those complaining hearing impairment. In common health symptoms majority (58.1\%) complained of pain and swelling of joint and unmet need for consultation was higher among those with Giddiness and fainting (56.6\%).(Table 2) In chronic illnesses, 34\% reported to have hypertension which was commonest and almost 
all the participants with pulmonary disease and cancer were visiting health care facilities regularly. This study found the prevalence of at least one unmet health care need to be $64.9 \%$ among the studied participants. (Table 3)

Table 2 Unmet health care needs for different illness $(n=530)$

Table 3 Prevalence of unmet health care needs

\begin{tabular}{|l|l|l|l|}
\hline Types of Unmet Need & Number of Subjects & Prevalence in specific Needs & Prevalence in whole sample \\
\hline Lack of management of Hypertension & 12 & $6.7 \%$ & $2.3 \%$ \\
\hline Lack of management of Diabetes & 3 & $3.9 \%$ & $0.6 \%$ \\
\hline Lack Of management of Cardiovascular diseases & 2 & $6.67 \%$ & $0.38 \%$ \\
\hline Lack of management of Near Sightedness & 161 & $52.3 \%$ & $30.4 \%$ \\
\hline Lack of management of Far Sigtedness & 146 & $53.7 \%$ & $27.5 \%$ \\
\hline Lack of management of Hearing problem & 126 & $79.7 \%$ & $23.8 \%$ \\
\hline Lack of management of Dental problems & 224 & $79.4 \%$ & $42.3 \%$ \\
\hline At least one unmet health care need & 344 & - & $64.9 \%$ \\
\hline
\end{tabular}

This table shows the prevalence of unmet health care needs for different participants in whole sample as well as in those with specific needs

The higher proportion of participant with at least one unmet health care need was prevalent among the age group of 80 years and above (76.7\%), female gender (69.2\%), dalit ethnicity (86.8\%), hindu by religion (66.7\%), currently single (71.4\%), illiterate (74.9\%), lowest per capita income (78.7\%), those below poverty line (75.1\%), those living alone (76.5\%), complaining of difficulty doing daily activities (87.3\%) and difficulty leaving home without help (88.4\%), not involved in social activity (68.8\%), with poor self - reported health status (82.8\%), who choose to visit nowhere for their health problem (85.2\%), stating more than 30 minutes to reach hospital (68.4\%), use of health facility more than a year ago (73.9\%), with no health insurance (67.1\%), not satisfied with health care services (74.7\%), no knowledge about health policies regarding elderly (71.5\%) and depressive symptoms (77.2\%). (Table 4)

(Table 4 Association of different variables with unmet health care needs)

In binary logistic regression analysis, the participants of age group 80 years, Dalit by ethnicity, illiterate, those with lesser income, those complaining of difficulty leaving home without help, those going nowhere taking home remedy, those reporting more than 30 minutes to reach health facility and those with depressive symptoms were found at higher odds of having unmet health care needs with significant association. The participants visiting their respective welfare camps for their illness were seen to be protective with odds of 0.138 . (Table 5)

Table 5 Binary logistic regression of different variables with at least one unmet health care need

\section{Discussion}

Elderly are the dependent population of the country. Developing countries like ours, lack an effective way to cope with emerging problems of the elderly. We should explore the resources to inform the policymakers of the required step forward in fulfilment of the needs of the elderly population.

\section{Prevalence of Unmet Health Care Needs}

At least one unmet health care need was reported by $64.9 \%$ and prevalence increased with increasing age group reaching $76.7 \%$ in people aged 80 years and older. Similar to this in a study done in French elderly the unmet health care needs were reported by $23.0 \%$ of the study population and prevalence increased with age, reaching $46.1 \%$ in people aged 95 and older. The prevalence of unmet need was more in our study compared to study in French elderly but similar in a way that study also reported unmet needs for visual impairment, hearing care and dental care to be $44.2 \%, 88.0 \%$, and $76.4 \%$ respectively. (6) These similar 
and higher proportion of unmet needs for specific health care in these diverse countries indicates the vulnerability of the elderly population for achieving a healthy life.

There were marked differences in findings of a similar study done in another city of Nepal regarding the proportion of unmet health care needs which may be due to the study location, study design and also our study constituted almost double sample size. (11) Also our country Nepal is a home of geographical and cultural diversity that creates a difference in availability, accessibility, and acceptability of different health services and the way the population act and takes responsibility for their health.

In our study, $1.9 \%(3 / 158)$ of those with the hearing problem was found using hearing aid similar to the study in India which reported only $1.47 \%(6 / 257)$ of the hearing impaired were using a hearing aid. (26)

\section{Predictors of Unmet health care needs}

Similar to our study French study revealed age, regular homebound status, tobacco smoking, poor economic situation, low level of former employment, limitations in IADL and depressive status as the risk of having unmet health care needs. (6)

Similar to our study in a study done in Serbia the probability for those least reporting unmet health care needs included those with higher education and who belong to the richest quintile but differ in work status as unemployed were seen protective and unemployed elderly in our study were seen with higher odds of having unmet health care needs. (9)

In a study Unmet needs of the elderly in a rural population of Meerut, about half (46.3\%) elderly were not aware of any geriatric welfare services similar to our study where more than half $51.7 \%$ did not know about existing health policies for elderly. (7) This may be due to the lack of proper information, education and communication activities targeting the elderly and a neglecting attitude towards the elderly.

\section{Conclusion}

The Unmet health care Needs of Elderly was faced by more than 3/5th of the participant. Continuous intervention program focusing on healthy ageing should be conducted to motivate elderly people for health care utilization. Geriatric counselling Centre should be commenced and health care utilization should be exercised by the whole community with active participation in betterment of health. Low knowledge regarding policies in elderly should be tackled by making them aware about the existing policies, provisions and should be educated to mitigate risk factors and utilize health services for prolonging their life and leading a quality life. The unmet health care needs were more prevalent among elderly living alone, which indicate is a great role of family support in healthy ageing. So, family members should develop an effective way to cope with the problems of ageism. The health policies should priorities the vulnerable and health service should be made available at the primary level with geriatric specialized one door policy capable of addressing common health problems among the elderly.

\section{List Of Abbreviations}

GAWI: Global Age Watch Index

BDI - II : Beck Depression Inventory $2^{\text {nd }}$ Edition

IRC: Institutional Review committee

HMIS: Health Information Management System

USD: U.S Dollar

\section{Limitations}

- Population proportionate sample size were taken due to the unavailability of the elderly population in each ward and a higher number of the total population doesn't confirm the higher number of the ageing population.

- The common presenting symptoms was taken as felt needs by the participants which couldn't be confirmed as there could be an exaggeration of symptoms.

- This study tried to explore the common health problems among the elderly population yet missed one of the major issue of cognitive impairment.

- Mental health self-reports are sometimes subject to bias because of a general community stigma towards mental illness in Nepal. (28)

\section{Declarations}

- Ethics approval and consent to participate was obtained from Institutional review committee (IRC) of B.P Koirala Institute of Health Sciences (Code No. IRC/1163/017). Written consent was taken from every participant before their participation and the motive of the study was clearly stated. Literate participant signed the consent form and finger print was taken from illiterate ones.

- Consent for publication: There is no any personal identification or information in this study. 
- Availability of data and materials: Data used in generating result of this study can be made available from author whenever needed on request. It can also be assessed from link:https://drive.google.com/file/d/1RQZWlw1w-Pzsc5vW_HUAo-Oe7Ztboo1p/view?usp=sharing

- Competing Interest: The authors declare that they have no competing interest for this study.

- Funding: There is no any source of funding and the expenses of study was carried out by author.

- Authors Contribution: Every author has contributed in the study. Dr MP and Mrs AO were involved from proposal writing, data collection to data analysis, result generation and writing of manuscript. Professor Dr A, Dr DKY, Dr RBSah and Mr AC were involved in supervising and edition of the article and helped in every step from proposal writing, obtaining ethical approval to fulfillment of this research. All authors have read and approved the manuscript.

- Acknowledgement: This article is a result of great deal of support and motivation. It is a pleasure to thank who made this research article possible with their continuous help, guidance, cooperation and encouragement, providing me with everything I needed. I would like to express my deepest gratitude to my supervisors and friends for their guidance and support. I am Indebted to participants of this study for providing me their valuable time, information, help and cooperation.

\section{References}

1. Park K. Park's Textbook of Preventive \& Social Medicine - 23 Edition. 23rd ed. 2015. 594 p.

2. Planning N, Secretariat C. National Populatio n and Housing Census 2011 Central Bu reau of Statistics. 2012;1.

3. Policy F, Development TO. AGEING SCENARIO IN NEPAL: 1 p.

4. Global rankings table | Data | Global AgeWatch Index 2015 [Internet]. [cited 2019 Apr 13]. Available from: https://www.helpage.org/globalagewatch/global-rankings-table/

5. WHO | What is Healthy Ageing? WHO [Internet]. 2018 [cited 2018 Aug 4]; Available from: http://www.who.int/ageing/healthy-ageing/en/

6. Herr M, Arvieu J-J, Aegerter P, Robine J-M, Ankri J. Unmet health care needs of older people: prevalence and predictors in a French cross-sectional survey. European journal of public health [Internet]. 2014;24(5):808-13. Available from: http://www.pubmedcentral.nih.gov/articlerender.fcgi? artid=4168041\&tool=pmcentrez\&rendertype=abstract

7. Goel P, Garg S, Singh J, Bhatnagar M, Chopra H, Bajpai S. Unmet needs of the elderly in rural population of Meerut. U. 2003;28(4):165-6.

8. Hoebel J, Rommel A, Schröder SL, Fuchs J, Nowossadeck E, Lampert T. Socioeconomic inequalities in health and perceived unmet needs for healthcare among the elderly in Germany. International Journal of Environmental Research and Public Health. 2017;14(10).

9. Popovic N, Terzic-Supic Z, Simic S, Mladenovic B. Predictors of unmet health care needs in Serbia; Analysis based on EU-SILC data. PLoS ONE. 2017;12(11):1-20.

10. Alonso J, Orfila F, Ruigómez A, Ferrer M, Antó JM. Unmet health care needs and mortality among Spanish elderly. American Journal of Public Health. 1997;87(3):365-70.

11. Kshetri DANBB, Smith WCS. Self-reported health problems, health care utilisation and unmet health care needs of elderly men and women in an urban municipality and a rural area of Bhaktapur District of Nepal. 2011;14(June):127-31.

12. World A, Case T, Data N, World A, Statistics N, Isbn C, et al. Copyright @ National Academy of Sciences. All rights reserved. Unless otherwise indicated, all materials in this PDF File are copyrighted by the National Academy of Sciences. Distribution, posting, or copying is strictly prohibited without written permiss. 2001. $16 \mathrm{p}$.

13. Shrestha L. Geriatric Health in Nepal: Concerns and Experience. 2012;15(2):144-8.

14. Nations U. World Population Ageing. 2017. 2 p.

15. Diwan S, Moriarty D. A Conceptual Framework for Identifying Unmet Health Care Needs of Community Dwelling Elderly. Journal of Applied Gerontology [Internet]. 1995;14(1):47-63. Available from: http://search.proquest.com/docview/1761704232?accountid=27257\%5Cnhttp://sfxit.ugent.be/sfx_hogent? url_ver=Z39.88-

2004\&rft_val_fmt=info:ofi/fmt:kev:mtx:journal\&genre=article\&sid=ProQ:ProQ\%3Asocialservices\&atitle=A+Conceptual+Framework+for+ldentifying+Unmet

16. Package of Essential Non-communicable Diseases (PEN) [Internet]. [cited 2019 Feb 4]. Available from: http://mohp.gov.np/eng/program/free-healthprogramme/pen

17. Kohrt BA, Kunz RD, Koirala NR, Sharma VD, Nepal MK. Validation of a Nepali version of the Beck Depression Inventory. Nepalese Journal of Psychiatry. 2002;2(4):123-30.

18. Jackson-Koku G. Beck depression inventory. Occupational Medicine. 2016;66(2):174-5.

19. Citizens S, Act 2006. Senior Citizens Act, 2063 ( 2006 ). 2006;2063(22):1-18.

20. Swami HM, Bhatia MV, Dutt R, SPS B. A Community Based Study of the Morb idity Profile among the Elderly in Chandigarh, India. Bahrain Medical Bulletin. 2002;24(1):13-6.

21. Bista B, Sjipati DB, Pathak RS, Adhilkary U, Bajracchary G, Bhandari DR, et al. Population Monograph of Nepal, Volume 1: Population Dynamics. 2014.

22. Lustig N, Silber J. Introduction to the special issue on global poverty lines. Journal of Economic Inequality. 2016 Jun 1;14(2):129.

23. World Bank Group. Development Goals in an Era of Demographic Change. Vol. 53, Global Monitoring Report 2015/2016. 2016.

24. Nepal Rastra Bank [Internet]. [cited 2018 Oct 1]. Available from: https://www.nrb.org.np/fxmexchangerate.php

25. Kim J, Choe M, Chae YR. Prevalence and Predictors of Geriatric Depression in Community-Dwelling Elderly. Asian Nursing Research [Internet]. 2009;3(3):121-9. Available from: http://dx.doi.org/10.1016/S1976-1317(09)60023-2 
26. Thakur RP, Banerjee A, Nikumb VB. Health Problems Among the Elderly: A Cross-Sectional Study. Vol. 3, Annals of Medical \& Health Science Research. 2018. p. 19-25.

27. E S, K PJ, Ms T. the Health-Care Needs Among Older Persons in an Indonesian Urban Setting. Asian Journal of Pharmaceutical and Clinical Research [Internet]. 2017;10(7):233. Available from: https://innovareacademics.in/journals/index.php/ajpcr/article/view/18300

28. Davison KK, Birch LL. NIH Public Access. 2008;64(12):2391-404.

\section{Tables}

Table 1 Socio-demographic factors of participants $(n=530)$

\begin{tabular}{|c|c|c|c|}
\hline Characteristic & Categories & Frequency (n) & Percent (\%) \\
\hline \multirow{3}{*}{ Age Distribution } & 60-69 years & 218 & 41.4 \\
\hline & 70-79 years & 209 & 39.4 \\
\hline & $>80$ years & 103 & 19.4 \\
\hline \multirow[t]{2}{*}{ Gender } & Male & 270 & 50.9 \\
\hline & Female & 260 & 49.1 \\
\hline \multirow{4}{*}{ Ethnicity } & Dalit & 53 & 10.0 \\
\hline & Janajati & 224 & 42.3 \\
\hline & Madhesi/ Muslim & 11 & 2.1 \\
\hline & Brahmin/Chettri & 242 & 45.6 \\
\hline \multirow[t]{2}{*}{ Religion } & Hindu & 454 & 85.7 \\
\hline & Others & 76 & 14.3 \\
\hline \multirow[t]{2}{*}{ Marital Status } & Currently Single & 192 & 36.2 \\
\hline & Currently Couple & 338 & 63.8 \\
\hline \multirow{3}{*}{ Type of house } & Kachha & 105 & 19.8 \\
\hline & Semi Pukka & 174 & 32.8 \\
\hline & Pukka & 251 & 47.4 \\
\hline \multirow{4}{*}{ Living Arrangement } & With Son & 406 & 76.6 \\
\hline & With Daughter & 55 & 10.4 \\
\hline & Couple Only & 52 & 9.8 \\
\hline & Alone & 17 & 3.2 \\
\hline \multirow{5}{*}{ Per capita Income in NRs Thousasnd } & $<43.2$ & 108 & 20.4 \\
\hline & $43.2-60$ & 122 & 23.0 \\
\hline & $60-80$ & 80 & 15.1 \\
\hline & $80-96$ & 119 & 22.5 \\
\hline & $>96$ & 101 & 19.1 \\
\hline \multirow[t]{2}{*}{ Economic status } & Below Poverty Line & 297 & 56.0 \\
\hline & Above Poverty line & 233 & 44.0 \\
\hline \multirow[t]{2}{*}{ Level of education } & Illiterate & 359 & 67.7 \\
\hline & Literate & 171 & 32.3 \\
\hline \multirow{6}{*}{ Work Status } & Paid Employee & 22 & 4.2 \\
\hline & Agriculture & 45 & 8.5 \\
\hline & Business & 47 & 8.9 \\
\hline & Homemaker & 110 & 20.8 \\
\hline & Retired & 43 & 8.1 \\
\hline & None & 263 & 49.6 \\
\hline
\end{tabular}


This table shows the different Social, Demographic and Economic characteristics of participant

Table 2: Unmet health care needs for different illness $(\mathrm{n}=530)$

\begin{tabular}{|c|c|c|c|c|c|}
\hline Common health problem & Felt need & Sought Consultation & Unmet needs for & Taking treatment who consulted & Unmet needs for treatment \\
\hline Near Sightedness & $308(58.2 \%)$ & $147(47.7 \%)$ & $161(52.3 \%)$ & $66(44.9 \%)$ & $81(55.1 \%)$ \\
\hline Far Sightedness & $272(51.3 \%)$ & $126(46.3 \%)$ & $146(53.7 \%)$ & $54(42.9 \%)$ & $72(57.1 \%)$ \\
\hline Hearing Difficulty & $158(29.9 \%)$ & $32(20.3 \%)$ & $126(79.7 \%)$ & $3(9.4 \%)$ & $29(90.6 \%)$ \\
\hline Dental Problems & $282(53.2 \%)$ & $58(20.6 \%)$ & $224(79.4 \%)$ & $39(67.2 \%)$ & $19(32.8 \%)$ \\
\hline \multicolumn{6}{|c|}{ Common presenting symptoms } \\
\hline Pain and swelling of joint & $308(58.1 \%)$ & $166(53.9 \%)$ & $142(46.1 \%)$ & $120(72.3 \%)$ & $46(27.7 \%)$ \\
\hline Limitation of movement & $45(8.5 \%)$ & $27(60.0 \%)$ & $18(40 \%)$ & $20(74.1 \%)$ & $7(25.9 \%)$ \\
\hline Indigestion /HeartBurn & $122(23.0 \%)$ & $61(50 \%)$ & $61(50 \%)$ & $50(82 \%)$ & $11(28 \%)$ \\
\hline Backache & $139(26.2 \%)$ & $66(47.5 \%)$ & $73(52.5 \%)$ & $53(80.3 \%)$ & $13(19.7 \%)$ \\
\hline Excessive tiredness & $42(7.9 \%)$ & $20(47.6 \%)$ & $22(52.4 \%)$ & $18(90 \%)$ & $2(10 \%)$ \\
\hline Breathlessness & $74(14.0 \%)$ & $45(60.8 \%)$ & $29(39.2 \%)$ & $35(77.8 \%)$ & $10(22.2 \%)$ \\
\hline Headache & $82(15.5 \%)$ & $38(46.3 \%)$ & $44(53.7 \%)$ & $26(68.4 \%)$ & $12(31.6 \%)$ \\
\hline Cough & $54(10.2 \%)$ & $28(51.9 \%)$ & $26(48.1 \%)$ & $26(92.9 \%)$ & $2(7.1 \%)$ \\
\hline Giddiness/ Fainting & $106(20.0 \%)$ & $46(43.4 \%)$ & $60(56.6 \%)$ & $30(65.2 \%)$ & $16(34.8 \%)$ \\
\hline Urgency for micturation & $84(15.8 \%)$ & $53(63.1 \%)$ & $31(36.9 \%)$ & $45(84.9 \%)$ & $8(15.1 \%)$ \\
\hline Pain/Difficulty in urination & $70(13.2 \%)$ & $41(58.6 \%)$ & $29(41.4 \%)$ & $30(73.2 \%)$ & $11(26.8 \%)$ \\
\hline Change in Bowel Habit & $68(12.8 \%)$ & $40(58.8 \%)$ & $28(41.2 \%)$ & $35(87.5 \%)$ & $5(12.5 \%)$ \\
\hline Itching of skin & $83(15.7 \%)$ & $38(45.8 \%)$ & $45(54.2 \%)$ & $29(76.3 \%)$ & $9(23.7 \%)$ \\
\hline Chest Pain & $30(5.7 \%)$ & $19(63.3 \%)$ & $11(36.7 \%)$ & $13(68.4 \%)$ & $6(31.6 \%)$ \\
\hline Swelling of limbs & $39(7.4 \%)$ & $26(66.7 \%)$ & $13(33.3 \%)$ & $14(53.8 \%)$ & $12(46.2)$ \\
\hline Wheezing & $8(1.5 \%)$ & $6(75 \%)$ & $2(25 \%)$ & $5(83.3 \%)$ & $1(16.7 \%)$ \\
\hline Nasal Congestion & $5(0.9 \%)$ & $3(60 \%)$ & $2(40 \%)$ & $1(33.3 \%)$ & $2(66.7 \%)$ \\
\hline Prolapse in female & $25(4.7 \%)$ & $9(36 \%)$ & $16(64 \%)$ & $2(22.2 \%)$ & $7(81.8 \%)$ \\
\hline Others & $30(5.7 \%)$ & $18(60.0 \%)$ & $12(40.0 \%)$ & 10(33.3\%) & $8(66.7 \%)$ \\
\hline
\end{tabular}

Figure Legend: This table shows different common health problems, self reported chronic illness among the participants their felt needs, unmet need for consultation and treatment.

Table 4 : Association of unmet health need with Study variables $(n=530)$ 


\begin{tabular}{|c|c|c|c|c|c|}
\hline \multirow[t]{2}{*}{ Characteristic } & \multirow[t]{2}{*}{ Category } & \multirow[t]{2}{*}{ Total } & \multicolumn{2}{|c|}{ Unmet need for health } & \multirow[t]{2}{*}{$\mathrm{p}$ value } \\
\hline & & & Yes n (\%) & No $n(\%)$ & \\
\hline \multirow[b]{3}{*}{ Age } & $60-69$ years & $218(41.1 \%)$ & $114(52.3 \%)$ & $104(47.7 \%)$ & \multirow{3}{*}{$<0.001$} \\
\hline & 70-79 years & $209(39.4 \%)$ & $151(72.2 \%)$ & $58(27.8 \%)$ & \\
\hline & $\geq 80$ years & $103(19.4 \%)$ & $79(76.7 \%)$ & $24(23.3 \%)$ & \\
\hline \multirow[b]{2}{*}{ Gender } & Male & $270(50.9 \%)$ & $164(60.7 \%)$ & $106(39.3 \%)$ & \multirow[b]{2}{*}{0.041} \\
\hline & Female & $260(49.1 \%)$ & $180(69.2 \%)$ & $80(30.8 \%)$ & \\
\hline \multirow[b]{3}{*}{ Ethnicity } & Dalit & $53(10 \%)$ & $46(86.8 \%)$ & $7(13.2 \%)$ & \multirow[b]{3}{*}{0.002} \\
\hline & Janajati & $235(44.4 \%)$ & $145(61.7 \%)$ & $90(38.3 \%)$ & \\
\hline & BrahminChettri & $242(45.6 \%)$ & $153(63.2 \%)$ & $89(36.8 \%)$ & \\
\hline \multirow[t]{2}{*}{ Religion } & Hindu & $454(85.7 \%)$ & $303(66.7 \%)$ & $151(33.3 \%)$ & \multirow[b]{2}{*}{0.031} \\
\hline & Others & $76(14.3 \%)$ & $41(53.9 \%)$ & $35(46.1 \%)$ & \\
\hline \multirow[b]{2}{*}{ Marital status } & Currently Couple & $338(63.8 \%)$ & $207(61.2 \%)$ & $131(38.8 \%)$ & \multirow[b]{2}{*}{0.019} \\
\hline & Currently Single & 192(36.2\%) & $137(71.4 \%)$ & $55(28.6 \%)$ & \\
\hline \multirow[b]{2}{*}{ Literacy } & Illiterate & $359(67.7 \%)$ & $269(74.9 \%)$ & $90(25.1 \%)$ & \multirow[b]{2}{*}{$<0.001$} \\
\hline & Literate & $171(32.3 \%)$ & $75(43.9 \%)$ & $96(56.1 \%)$ & \\
\hline \multirow{5}{*}{ Per capita income in NRs thousand } & $<43.2$ & $108(20.4 \%)$ & $85(78.7 \%)$ & $23(21.3 \%)$ & \multirow[b]{5}{*}{$<0.001$} \\
\hline & $43.2-60$ & $122(23.0 \%)$ & $90(73.8 \%)$ & $32(26.2 \%)$ & \\
\hline & $60-80$ & $80(15.1 \%)$ & $60(75.0 \%)$ & $20(25.0 \%)$ & \\
\hline & $80-96$ & $119(22.5 \%)$ & 73(61.3\%) & $46(38.7 \%)$ & \\
\hline & $>96$ & $101(19.1 \%)$ & $36(35.6 \%)$ & $65(64.4 \%)$ & \\
\hline \multirow[t]{2}{*}{ Poverty Status } & Below Poverty & $297(56 \%)$ & $223(75.1 \%)$ & $74(24.9 \%)$ & \multirow[b]{2}{*}{$<0.001$} \\
\hline & Above Poverty & $233(44 \%)$ & $121(51.9 \%)$ & $112(48.1 \%)$ & \\
\hline \multirow[b]{4}{*}{ Living Arrangement } & Living with Son & $406(76.6 \%)$ & $272(67.0 \%)$ & $134(33.0 \%)$ & \multirow[b]{4}{*}{0.037} \\
\hline & Living with daughter & $55(10.4 \%)$ & $34(61.8 \%)$ & $21(38.2 \%)$ & \\
\hline & Couple Only & $52(9.8 \%)$ & $25(48.1 \%)$ & $27(51.9 \%)$ & \\
\hline & Alone & $17(3.2 \%)$ & $13(76.5 \%)$ & $4(23.5 \%)$ & \\
\hline \multirow[t]{2}{*}{ Difficulty in daily activities } & Yes & $102(19.2 \%)$ & $89(87.3 \%)$ & $13(12.7 \%)$ & \multirow[b]{2}{*}{$<0.001$} \\
\hline & No & $428(80.8 \%)$ & $255(59.6 \%)$ & $173(40.4 \%)$ & \\
\hline \multirow[t]{2}{*}{ Difficulty leaving home } & Yes & $69(13.0 \%)$ & $61(88.4 \%)$ & $8(11.6 \%)$ & \multirow[b]{2}{*}{$<0.001$} \\
\hline & No & $461(87.0 \%)$ & $283(61.4 \%)$ & $178(38.6 \%)$ & \\
\hline Involvement in social activity & Yes & $177(33.4 \%)$ & $101(57.1 \%)$ & $76(42.9 \%)$ & \\
\hline & No & $353(66.6 \%)$ & $243(68.8 \%)$ & $110(31.2 \%)$ & 0.01 \\
\hline & Good & $92(17.4 \%)$ & $43(46.7 \%)$ & $49(53.3 \%)$ & \\
\hline Solf Ronorted Hoalth & Average & $275(51.9 \%)$ & $166(60.4 \%)$ & $109(39.6 \%)$ & $=0001$ \\
\hline & Poor & $163(30.8 \%)$ & $135(82.8 \%)$ & $28(17.2 \%)$ & \\
\hline & Hospital & $311(58.7 \%)$ & 197(63.3\%) & $114(36.7 \%)$ & \\
\hline & Medical Shop & $55(10.4 \%)$ & $41(74.5 \%)$ & $14(25.5 \%)$ & \\
\hline
\end{tabular}




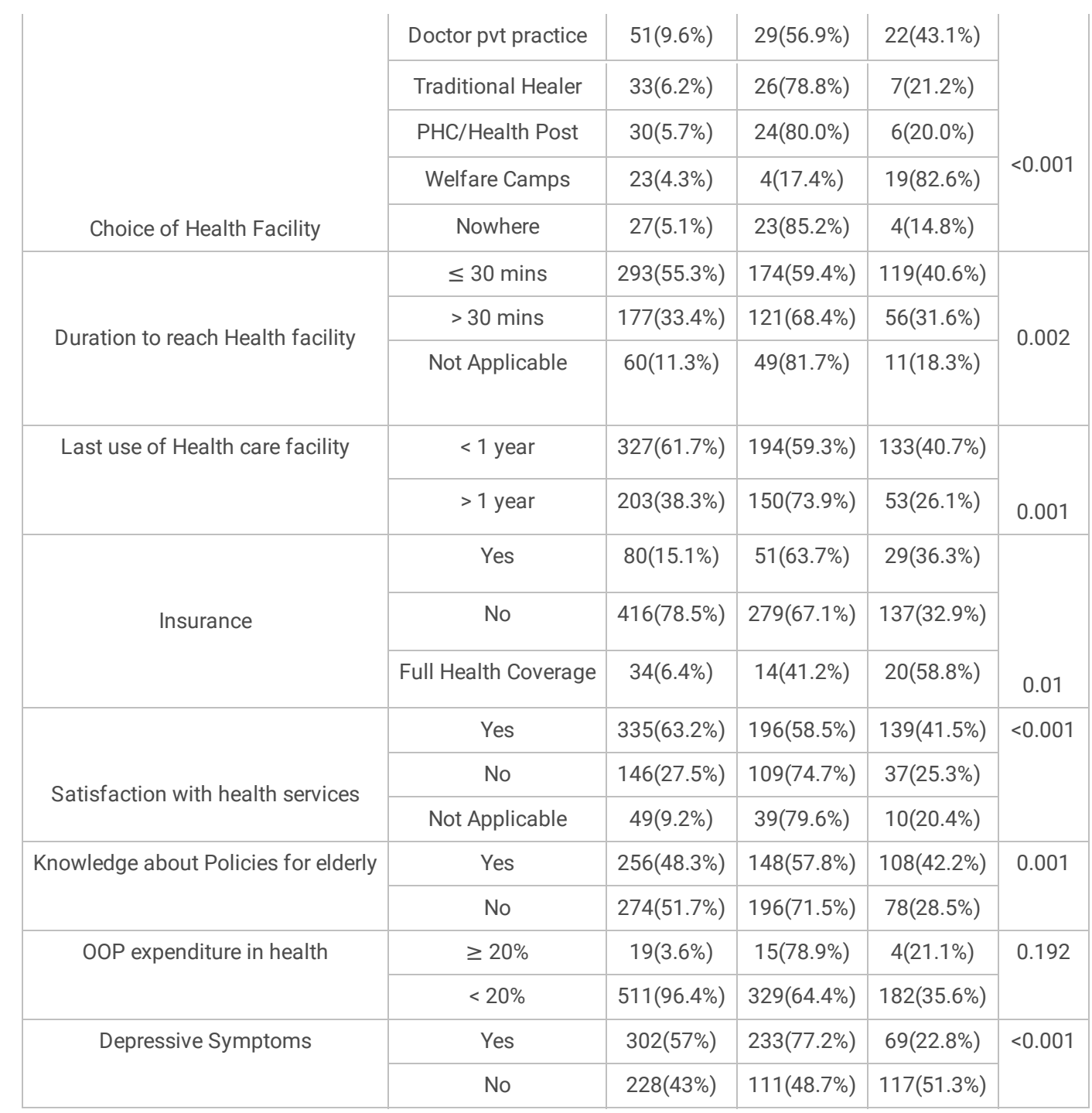

This is a table showing association of different studied variables with atleast one unmet health care needs among the studied population

Table 5: Binary logistic regression of different variables with at least one unmet health care need 


\begin{tabular}{|c|c|c|c|c|c|}
\hline \multirow[b]{2}{*}{ Characteristic } & \multirow[b]{2}{*}{ Categories } & \multirow[b]{2}{*}{$P$} & \multirow[b]{2}{*}{ aOR } & \multicolumn{2}{|c|}{$95 \%$ C.I. for aOR } \\
\hline & & & & Lower & Upper \\
\hline \multirow[t]{3}{*}{ Age } & $60-69$ years & & REF & & \\
\hline & $70-79$ years & .000 & 2.807 & 1.680 & 4.688 \\
\hline & $\geq 80$ years & .003 & 2.861 & 1.445 & 5.665 \\
\hline \multirow[t]{3}{*}{ Ethnicity } & Brahmin/Chettri & & REF & & \\
\hline & Dalit & .010 & 3.689 & 1.372 & 9.921 \\
\hline & Janajati & .002 & 2.629 & 1.436 & 4.813 \\
\hline \multirow[t]{2}{*}{ Education } & Literate & & REF & & \\
\hline & Illiterate & .001 & 2.444 & 1.458 & 4.097 \\
\hline \multirow[t]{5}{*}{ Per capita income in NRs thousand } & $>96$ & & REF & & \\
\hline & $<43.2$ & .000 & 4.666 & 2.160 & 10.077 \\
\hline & $43.2-60$ & .001 & 3.079 & 1.546 & 6.134 \\
\hline & $60-80$ & .000 & 4.266 & 1.957 & 9.298 \\
\hline & $80-96$ & .000 & 3.475 & 1.809 & 6.675 \\
\hline \multirow[t]{2}{*}{ Difficulty leaving home without help } & No & & REF & & \\
\hline & Yes & .011 & 3.231 & 1.306 & 7.992 \\
\hline \multirow[t]{3}{*}{ Self Reported Health status } & Good & & REF & & \\
\hline & Average & .045 & 1.862 & 1.015 & 3.417 \\
\hline & Poor & .009 & 2.797 & 1.300 & 6.020 \\
\hline \multirow[t]{7}{*}{ Choice of health facility } & Hospital & & REF & & \\
\hline & Medical Shop & .014 & 2.859 & 1.240 & 6.591 \\
\hline & Doctors private practice & .749 & 1.137 & .519 & 2.491 \\
\hline & Traditional healer & .110 & 2.474 & .815 & 7.515 \\
\hline & PHC/Health Posts & .003 & 5.186 & 1.723 & 15.605 \\
\hline & Welfare camps & .005 & .138 & .035 & .548 \\
\hline & Nowhere & .001 & 9.315 & 2.400 & 36.155 \\
\hline \multirow[t]{2}{*}{ Time to reach health facility } & $<30$ Minutes & & REF & & \\
\hline & > 30 Minutes & .003 & 2.481 & 1.369 & 4.496 \\
\hline \multirow[t]{3}{*}{ Depressive symptoms } & No & & REF & & \\
\hline & Yes & .010 & 1.887 & 1.163 & 3.060 \\
\hline & Constant & .000 & .093 & & \\
\hline
\end{tabular}

This is a table showing logistic regression for different variables and the odds ratio are calculated by backward logistic model and were adjusted for variables which seemed to have strong association in cross tab. 